\title{
Low temperature strategy to synthesize highly ordered mesoporous silicas with very large pores
}

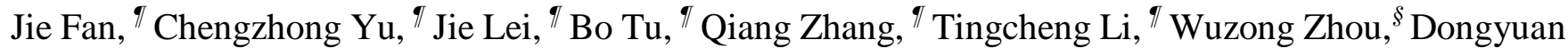
$\mathrm{Zhao}^{\pi_{*}}$

\section{Supporting Information:}

Synthesis of LP-FDU-12: Mesoporous silica was synthesized by using block copolymer and organic solvent as the templates with additive of inorganic salts. The synthesis composition (in molars) TEOS/F127/TMB/KCl/HCl/ $/ \mathrm{H}_{2} \mathrm{O}$ was 1.00/0.0037/0.50/3.36/6.00/155. A typical synthesis was as follows: $0.50 \mathrm{~g}$ of triblock copolymers $\mathrm{EO}_{106} \mathrm{PO}_{70} \mathrm{EO}_{106}$ (Pluronic F127), $0.60 \mathrm{~g}$ of 1,3,5-trimethylbenzene (TMB) and $2.5 \mathrm{~g}$ of $\mathrm{KCl}$ were dissolved in $30 \mathrm{ml}$ of $2 \mathrm{M} \mathrm{HCl}$ at $15 \pm 0.1^{\circ} \mathrm{C}$. After $2 \mathrm{~h}$ stirring, $2.08 \mathrm{~g}$ of tetraethyl orthosilicate (TEOS) was added to this solution. After stirring for $24 \mathrm{~h}$ at $15^{\circ} \mathrm{C}$, the mixture was transferred into an autoclave and heated at $100^{\circ} \mathrm{C}$ for $24 \mathrm{~h}$. As-made products were obtained by filtration and dried at room temperature in air. For the high-temperature hydrothermal treatment, $0.50 \mathrm{~g}$ of as-made products was added to a solution of $30 \mathrm{ml} 2 \mathrm{M} \mathrm{HCl}$ in an autoclave and the mixture was heated at desired temperature for another $48 \mathrm{~h}$ (denoted S-15-Y, where 15 refers to the synthesis temperature and $\mathrm{Y}$ is the hydrothermal treatment temperature). The organic templates were rapidly removed by recently developed microwave assisting digestion to obtain the final large pore FDU-12 materials (LP-FDU-12). (Tian; B. Z. et al. Chem. Commun., 2002, 1186) 
SI-1 Physicochemical properties of mesoporous silica LP-FDU-12 prepared at different temperature

\begin{tabular}{|c|c|c|c|c|c|}
\hline Samples $^{a}$ & $\begin{array}{l}\text { Unit cell } a \\
/ \mathrm{nm}\end{array}$ & $\begin{array}{l}\text { Cavity size }{ }^{b} \\
/ \mathrm{nm}\end{array}$ & $\begin{array}{l}\text { Entrance size }{ }^{c} \\
/ \mathrm{nm}\end{array}$ & $\begin{array}{l}\text { Pore volume } \\
/ \mathrm{cm}^{3} \mathrm{~g}^{-1}\end{array}$ & $\begin{array}{l}\text { BET Surface } \\
\text { area } \\
/ \mathrm{m}^{2} \mathrm{~g}^{-1}\end{array}$ \\
\hline S-60-100 & 26.0 & 12.7 & $<4$ & 0.65 & 619 \\
\hline S-50-100 & 26.8 & 12.7 & $<4$ & 0.64 & 610 \\
\hline S-40-100 & 29.3 & 14.1 & $<4$ & 0.68 & 677 \\
\hline S-30-100 & 29.0 & 14.1 & $<4$ & 0.60 & 575 \\
\hline S-23-100 & 29.5 & 14.1 & $<4$ & 0.80 & 666 \\
\hline S-18-100 & 31.7 & 14.1 & $<4$ & 0.85 & 345 \\
\hline S-17-100 & 33.1 & 16.7 & $<4$ & 0.61 & 569 \\
\hline S-16-100 & 37.5 & 16.7 & $<4$ & 0.63 & 595 \\
\hline S-15-100 & 44.5 & 22.3 & $<4$ & 0.89 & 643 \\
\hline S-50-140 & 27.0 & 15.4 & 10.9 & 0.82 & 338 \\
\hline S-18-140 & 32.0 & 16.6 & 10.6 & 0.85 & 345 \\
\hline S-16-140 & 37.5 & 21.3 & 10.7 & 0.94 & 397 \\
\hline S-15-140 & 44.5 & 27.3 & 16.6 & 0.94 & 271 \\
\hline
\end{tabular}

\footnotetext{
${ }^{a}$ The samples were designated as $\mathrm{S}-\mathrm{X}-\mathrm{Y}$, where $\mathrm{X}$ indicates the synthesis temperature, and $\mathrm{Y}$ indicates the temperature of hydrothermal treatment. ${ }^{b}$ Calculated from the adsorption branches of the $\mathrm{N}_{2}$ sorption isotherms based on the BdB sphere model. ${ }^{c}$ Calculated from the desorption branches of the $\mathrm{N}_{2}$ sorption isotherms based on the BdB sphere model.
} 
SI-2 XRD patterns of mesoporous silica LP-FDU-12 samples prepared with different synthesis temperature. The triblock copolymer templates were removed by microwave-assisting digestion method.
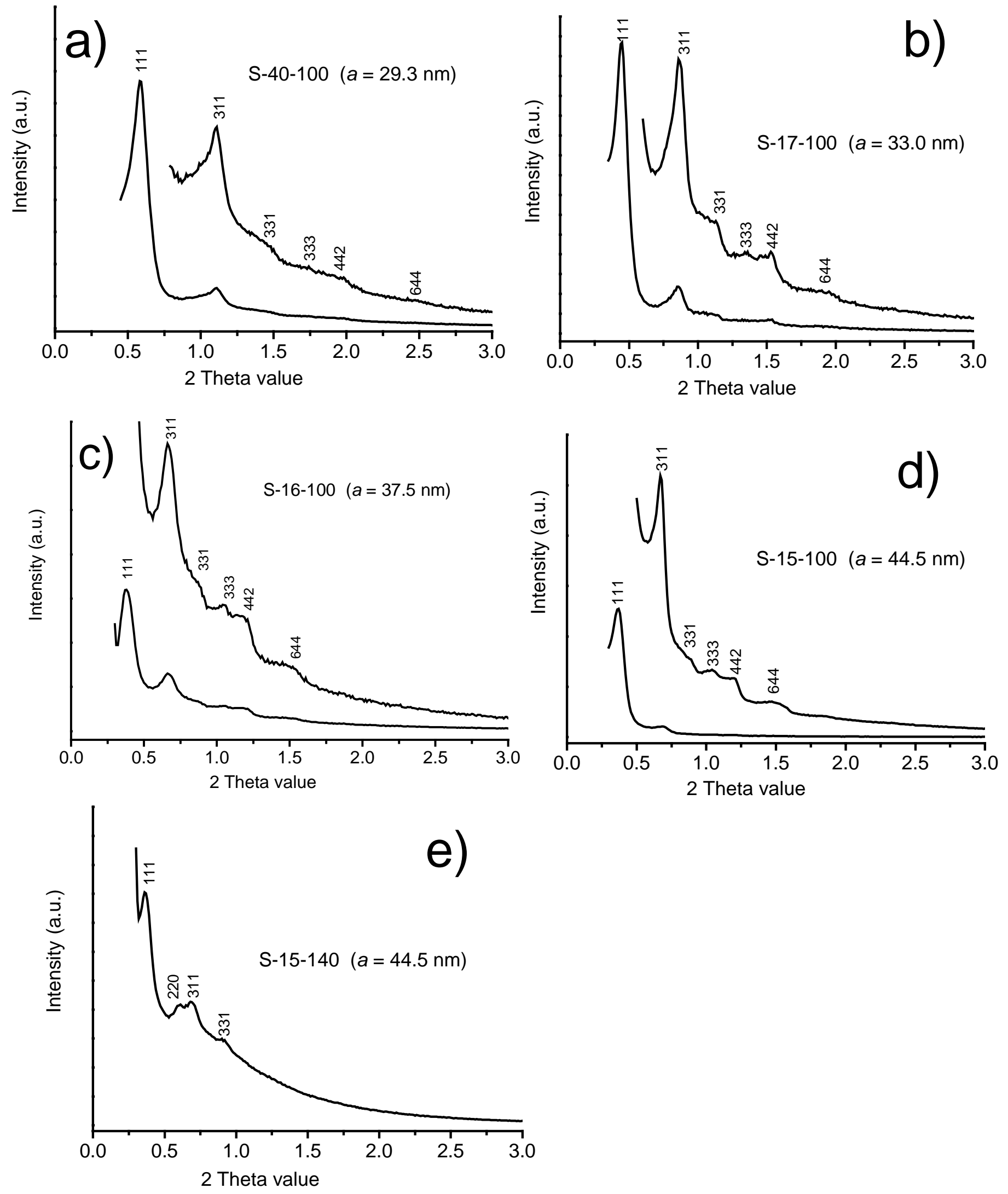
SI-3 Nitrogen sorption isotherms and pore size distribution plots of mesoporous silica LP-FDU-12 samples. a) and b) S-15-100, c) and d) S-15-140.
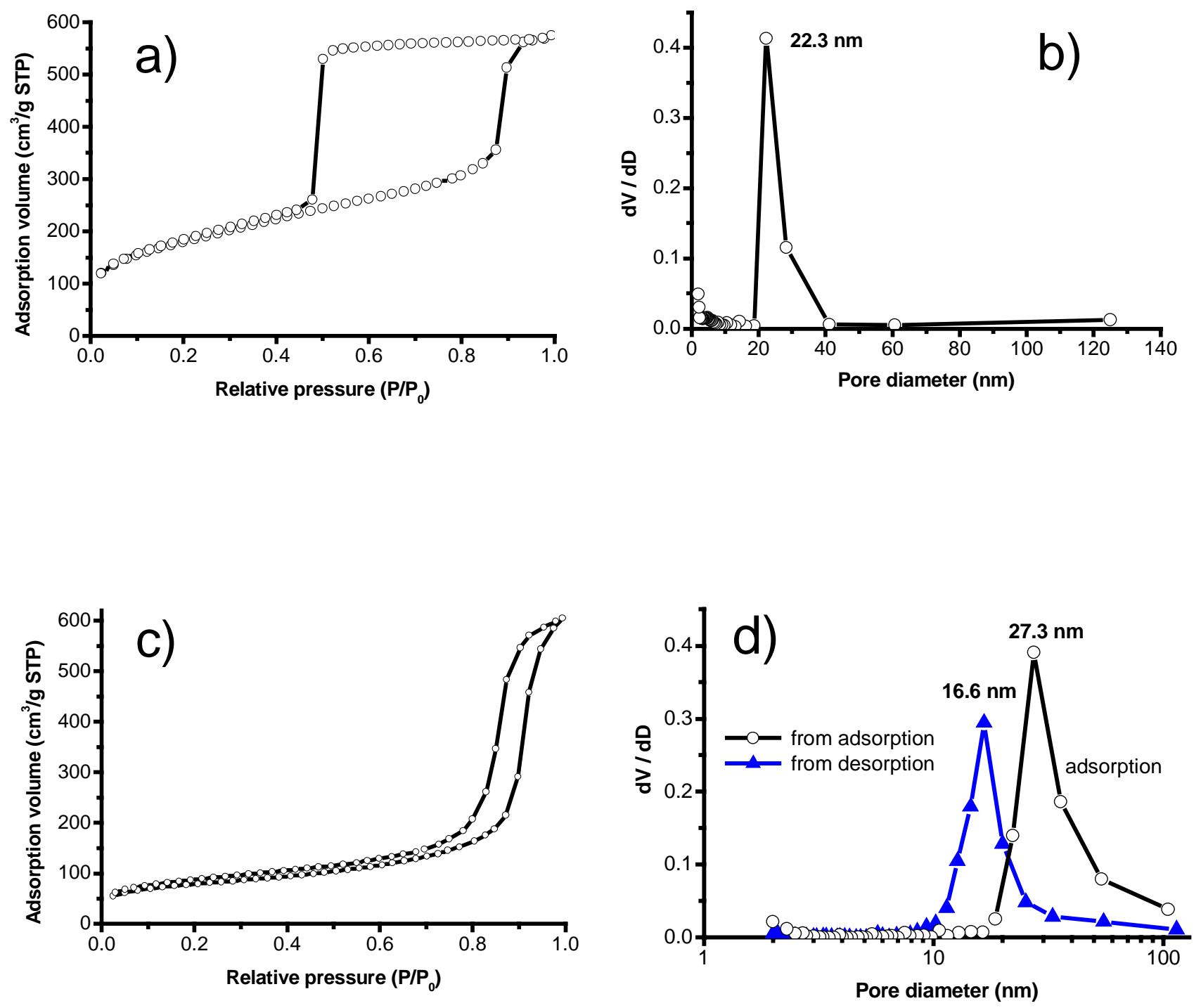
SI-4 XRD patterns of mesoporous silica LP-FDU-12 (S-18-130) prepared at $18^{\circ} \mathrm{C}$ with hydrothermal treatment $\left(130^{\circ} \mathrm{C}\right)$ and its carbon replica.
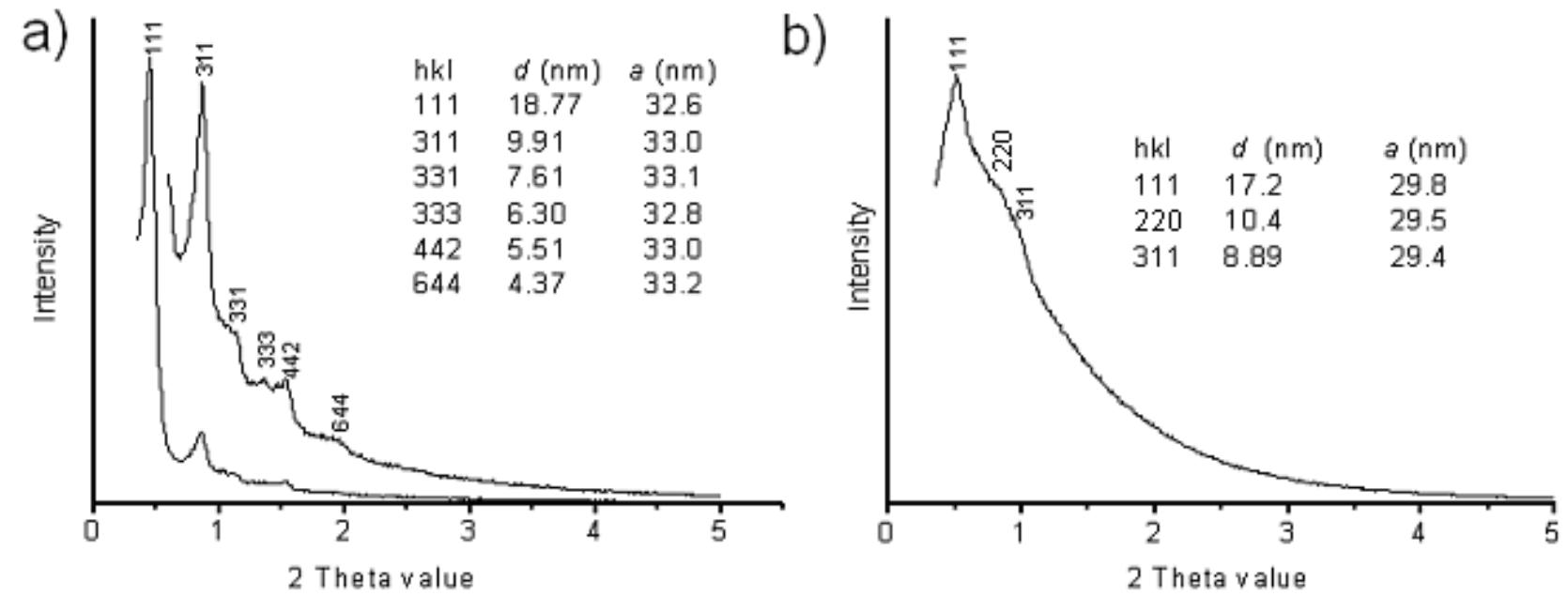
SI-5 TEM and the corresponding iFFT images of mesoporous carbon replicated from mesoporous silica

LP-FDU-12 viewed along a, b) [110], c, d) [112], and e, f) [223]
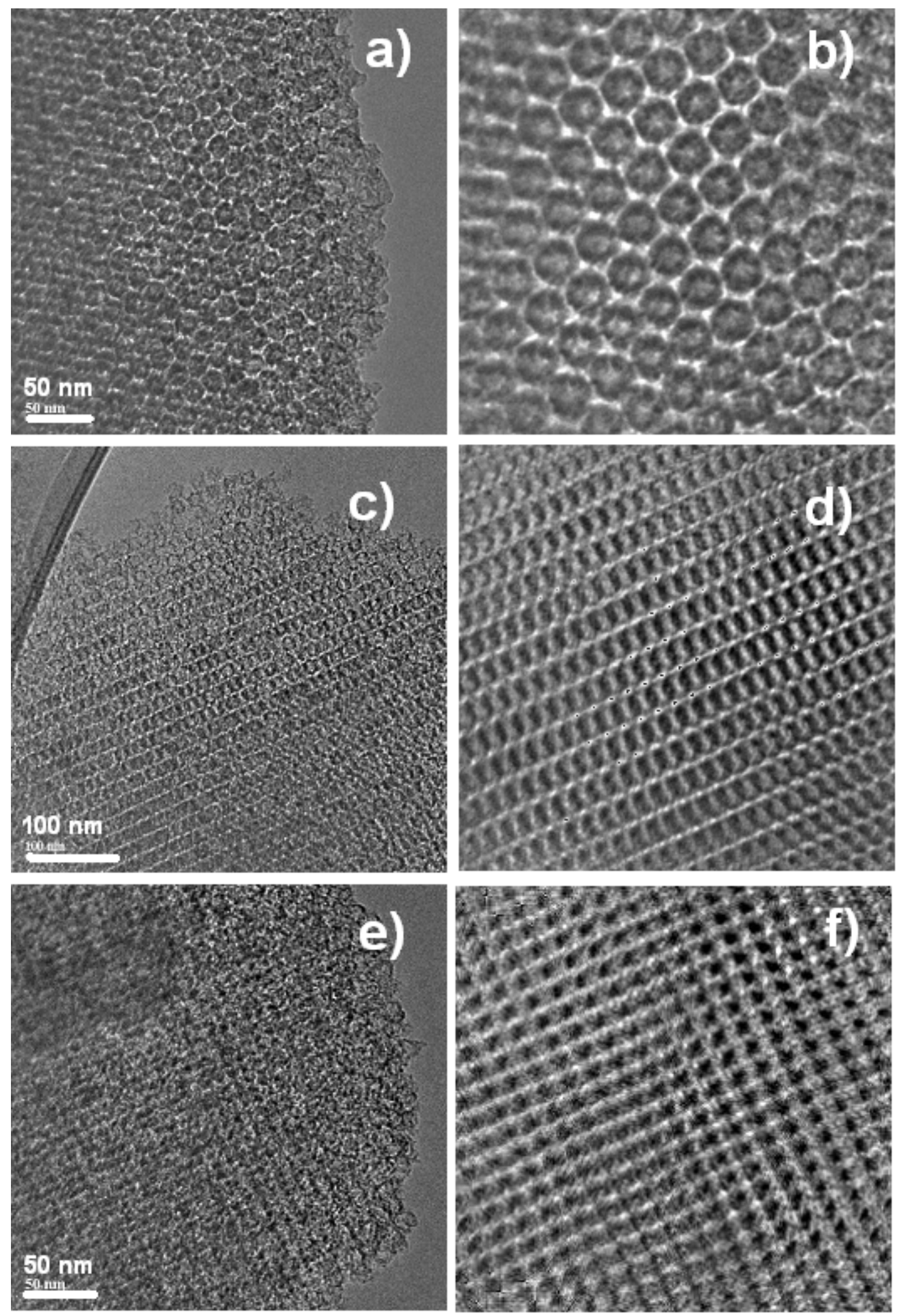
SI-6 a) Nitrogen sorption isotherms and b) pore size distribution plot (calculated from BJH model) of mesoporous carbon replicated from mesoporous silica LP-FDU-12 (S-18-130).
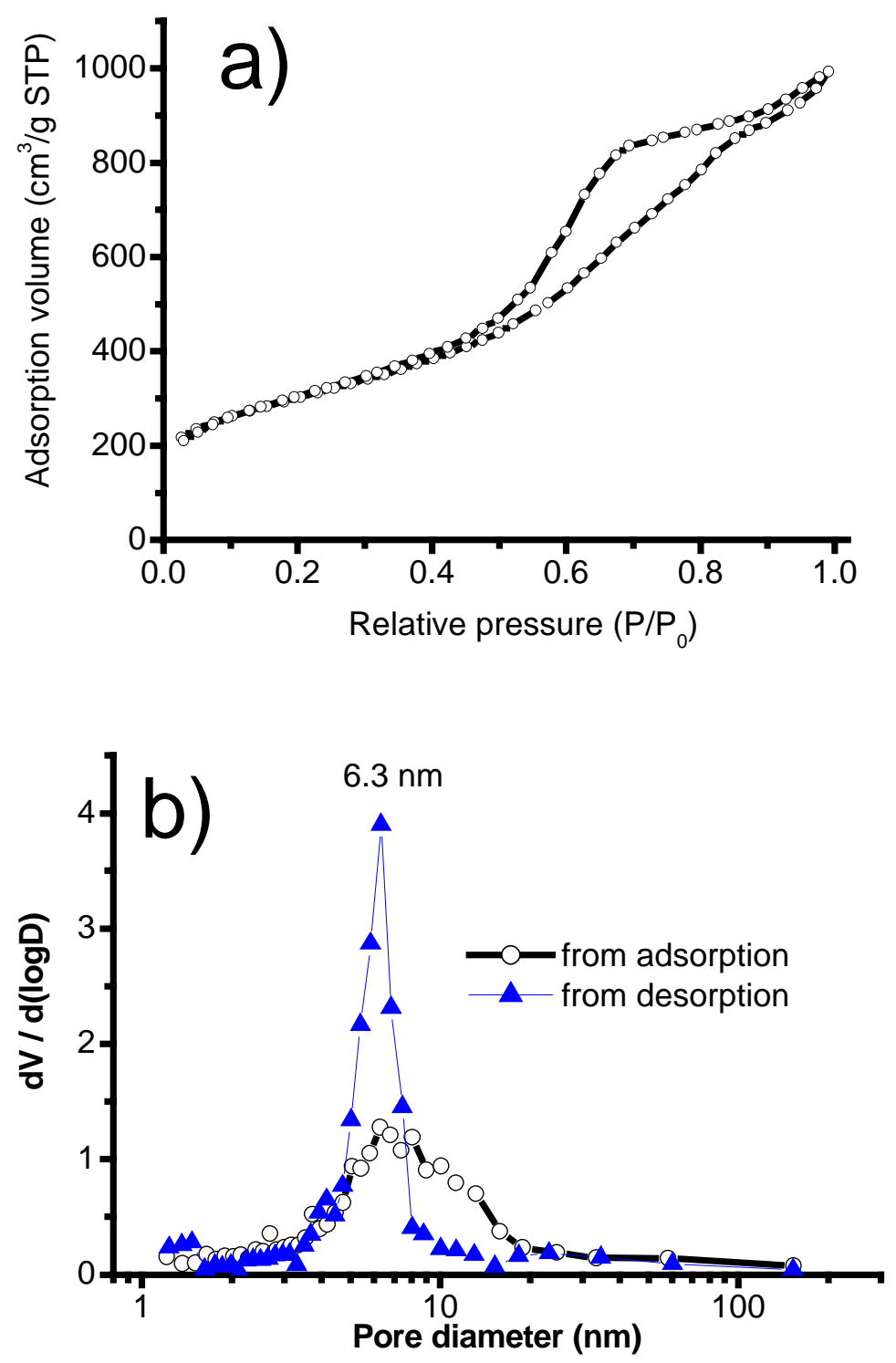